See discussions, stats, and author profiles for this publication at: https://www.researchgate.net/publication/249933196

\title{
Categories within the verb category: Learning the causative in Inuktitut
}

Article in Linguistics · January 1998

DOI: 10.1515/ling.1998.36.4.633

\section{CITATIONS}

18

1 author:

(2)

Shanley Allen

Technische Universität Kaiserslautern

79 PUBLICATIONS 1,002 CITATIONS

SEE PROFILE

Some of the authors of this publication are also working on these related projects:

Project Cross-linguistic structural priming View project

Project ACQDIV: acquisition processes in maximally diverse languages View project 


\section{Categories within the verb category: learning the causative in Inuktitut*}

SHANLEY E. M. ALLEN

\section{Abstract}

How children learn the category "verb" as a grammatical construct has been the focus of much research over the past two decades. However, less attention has been paid to acquisition of smaller categories within the verb category. This paper uses data concerning the acquisition of causatives in Inuktitut to address the question of how smaller categories of verbs are learned. Inuktitut has one class of verbs that permits only a morphological causative, and a second class that permits either a morphological or a lexical causative depending on the semantics of the situation. Data from eight Inuktitut-speaking children aged 1;0 through 3;6 indicate that the distinction between these classes is acquired in three stages. During the first stage, the children use only lexical causatives and there is no evidence that they understand that these structures have a causative meaning component. During the second stage, they use the morphological causative indiscriminately across verb categories to issue commands. In addition, they begin to show productivity in their use of lexical causatives in that they alternate between intransitive and lexical-causative uses of the same verb root. By stage three, children have begun to distinguish the two classes of verbs with respect to causative constructions. Across the three stages outlined above, children apparently learn to use linguistic indicators of causation first in a situation-based way (i.e. for issuing commands) and later verb-by-verb, rather than employing a class-based approach to category formation. These results are analyzed in terms of similar studies in English and Hebrew. and in terms of a general phasal approach to cognitive and linguistic development.

\section{Introduction}

There has been much spiculation in the past couple of decades about how children learn verbs, and specifically how they learn the category 
"verb" as a unified construct. Researchers following a nativist approach to language acquisition typically find that children treat verbs as a grammatical category virtually from the beginning of acquisition, perhaps even as part of their innate language endowment (e.g. Pinker 1984; Radford 1990; Valian 1991; Gleitman 1990). Other researchers, following an empiricist approach, rather find that children initially learn verbs one by one as individual lexical items, and only well after the first acquisition of verbs do they posit a grammatical category of "verb" by which they treat all verbs in a similar rule-governed fashion (e.g. Berman 1986; Braine 1987; Bowerman 1990; Tomasello 1992; Pine et al. this issue). Several key findings relate to this question of early verb-category development. It is widely agreed that children do not tend to make form-category errors even from the earliest stages, such that children do not typically put verbal inflections on nominal roots, or violate combinatorial restrictions of word classes typical to the endstate grammar (Bloom 1970; Bowerman 1973; Brown 1973; Maratsos 1983); this would support a theory of early or innate category formation. On the other hand, children do not apply every combinatorial rule to every term in their vocabulary to which such a rule could apply (Maratsos 1983). Thus, children may inflect verbs or use verbs with auxiliaries at early stages, but it is most often the case that a given verb is used with only one auxiliary or inflection, and that a given inflection or auxiliary is used with only one verb, rather than all verbs in the vocabulary being used with all available inflections and auxiliaries (Ninio 1988; Lieven 1996; Pine et al. this issue); this evidence would support a theory of verb-by-verb learning. Finally, children tend to make errors in certain domains of verb use after an initial period of correct use, as in past tense formation (Marcus et al. 1992) and lexical causative formation (Bowerman 1974). These errors seemingly result from overgeneralized application of an otherwise productive rule to verbs that represent exceptions in the system and indicate a point of reorganization in the children's understanding of verbs such that they move from memorization of individual forms to category formation. This pattern is often called $U$-shaped development (Bowerman 1982). Irrefutable evidence of the existence of a verb category may only come relatively late in the acquisition process. Maratsos (1988) argues that proof of formation of a verb category is only clear once overgeneralization errors are encountered and once children show evidence of use of different inflections with the same verb, while Ninio (1988) states that distributional evidence is always suspect and that one must wait on deciding whether or not a given child has a verb category until he or she is mature enough to make grammaticality judgments.
The issue of category formation need not be restricted to the category of verbs as a whole, since various syntactic and semantic factors may divide the verb category into subcategories that children must also learn. For example, many languages have two classes of verbs with respect to causative formation: those that permit only analytic causatives (e.g. English fall and laugh) and those that permit either lexical or analytic causatives depending on the semantics of the situation (e.g. English break and explode). Analytic causatives may be either periphrastic, using a separate word to indicate causation (e.g. I made it fall, she made it break), or morphological, using a separate morpheme on the verb root to indicate causation (e.g. *I fall-made it, "she break-made it). Lexical causatives do not encode the causation component independently in a phonetically overt way, but their form is usually morphologically related to a noncausative intransitive of similar semantic content. In English, lexical causatives are typically alternating in that the same lexical item is used to denote both the transitive causative and intransitive noncausative event (e.g. she broke it vs. $i t$ broke). Suppletive forms in which a different lexical item is used for the two events are sometimes also termed lexical causatives (e.g. I dropped it vs. it fell). Where both analytic and lexical causatives are permitted for a given verb, there are usually semantic differences implied by the two forms resulting from differences in the degree of directness of causation, the degree of control maintained by the causee, whether the structure implies causation or permission, and whether the causation is manipulative or directive (for further details, see Shibatani 1976; Talmy 1976; Comrie 1985, 1989; Pederson 1991). Languages differ in which of the possible causative resources they employ; for example, English has no morphological causative forms, and English verbs vary in whether they have alternating or suppletive lexical causatives. For any given language, then, children must determine which causative resources that language employs and must divide their verb repertoire into subcategories depending on which type(s) of causative each verb permits.

The acquisition of causatives has been investigated in a number of languages including Brazilian Portuguese (Figueira 1984), English (Bowerman 1974; Lord 1979; Hochberg 1986; Maratsos et al. 1987; Braine et al. 1990), Hebrew (Berman 1982, 1993a, 1993b), Inuktitut (Allen 1996), Japanese (Morikawa 1990), and K'iche' Mayan (Pye 1994). Most of this work has focused on children's overgeneralization of the lexical causative to verbs that do not permit it in these languages, finding in general that language-jarticular phenomena are key in determining the source of the children's overgeneralizations (see Allen 1996: 138-150 for a summary). Some of $t$, is work has also focused explicitly on category 
formation; here I summarize representative findings for English (Bowerman 1974) and Hebrew (Berman 1982, 1993a, 1993b).

In her study of causative acquisition in English, Bowerman (1974) notices a clear difference in the pattern of acquisition between lexical and analytic causatives, which are permitted in this language with the restrictions noted above. Based on her diary records for two children, she finds that lexical causatives appear in spontaneous speech before analytic causatives and are produced in an adultlike way from the earliest ages. Analytic causatives appear later, around age $3 ; 0$ and at about the time that other structures involving cause-effect relations also start appearing. Interestingly, at this same point the children begin to produce utterances in which the lexical-causative structure is overgeneralized to verbs that do not normally permit it in the adult language (e.g. I'm singing him [= I'm making the musical cow toy sing], age 3;1). Bowerman concludes that the earliest appearances of lexical causatives are ones in which the children have not yet analyzed the causative component of the verb. Once they begin to understand the concept of causation, they initially assume that all verbs can be used as lexical causatives and only later reorganize their verb repertoire into two separate categories.

Berman $(1982,1993 \mathrm{~b})$ has studied causative acquisition of Hebrewspeaking children in both spontaneous speech and experimental settings. Hebrew verbs may appear in one of five binyan 'conjugation' patterns depending on their syntactic characteristics, and a change in transitivity is manifest by a change in binyan pattern. Four pairs of patterns are productive for alternations between causative and intransitive uses of the same verb, and children must learn to divide their verbs into corresponding categories. In a study of spontaneous speech of young Hebrewspeaking children, Berman (1982) finds that children between 1;6 and $2 ; 6$, typically at the early stages of clause formation, rarely use the same verb with more than one transitivity value and thus show no evidence of using Hebrew binyan patterns productively for such functions as marking syntactic distinctions of transitivity or expressing the semantic notion of causativity. Rather, children at this age use verbs mainly as unanalyzed amalgams and do not appear to have either a verb category or subcategories of verbs according to alternation patterns. Productive knowledge of the binyan pattern-alternation system appears around age three, as indicated by errors overgeneralizing certain alternations (including the causative-intransitive alternation) outside the established lexicon. This indicates the same sort of reorganizational process found in Englishspeaking children noted above and results in categorization of verbs with respect to the appropriate alternation patterns. An elicited production study of Hebrew-speaking children aged 2;0 through 8;0 confirms these findings (Berman 1993b). In this study, children were given pictures showing transitive causative and intransitive depictions of the same event (e.g. megalgel 'the boy is rolling the ball' vs. mitgalgel 'the ball is rolling'), based on real and novel Hebrew verbs. The experimenter described one picture, and the child was asked to describe the other, thus testing the children's knowledge of binyan pattern alternations involving causation. Children aged $2 ; 6-3 ; 0$ produced correct responses for only $37.5 \%$ of the items based on real Hebrew words (26\% for novel words), compared with $66 \%(59 \%)$ at age $3 ; 6-4 ; 0$, and $92.5 \%(70 \%)$ at age $7 ; 6-8 ; 7$. In addition, performance at the younger ages for real words varied substantially across test items, such that children were more successful with more familiar and frequent lexical items and alternation patterns. The most frequent alternation patterns were also produced most frequently for the novel test items. Berman (1993a) thus concludes that children proceed from item-based learning to lexical learning of pairs of isolated alternations, and only subsequently to an integrated construal of morphological transitivity as a whole, dividing verbs into their appropriate alternation categories based on Hebrew-specific facts.

The findings of both Bowerman and Berman concerning children's categorization of verbs with respect to causative resources are more consistent with an empirical than a nativist approach to language acquisition. Children in both languages produce unanalyzed verb forms at the earliest stages, only progressing around age three to productive use of causative resources indicating category development. This pattern fits well within the more general phasal approach to development outlined by Berman $(1986,1988)$ and Karmiloff-Smith $(1986,1992)$. This phasal approach argues that children go through well-defined general phases in various areas of cognitive and language development; I briefly outline Berman's phases here, which are more specific to language development (Berman 1986: 192-193). ${ }^{1}$ In the first phase, termed rote knowledge, children produce individual linguistic forms correctly but as unanalyzed amalgams. In the second early modifications phase, they contrastively alternate a few highly familiar items. Children begin to apply transitional, nonnormative but partly productive rules in the third phase involving interim schemata. The fourth phase is characterized by rule knowledge, in which grammaticization involves strict adherence to rules coupled with some lacunae and insufficient constraints. Finally, phase five shows endstage usage; in this phase rule application is constrained by adult norms and conventions, with increasing variation of style and register. The studies of causative development in English and Hebrew reported above show that children go through each of these phases in their development of verb categories with relation to causative forms. In addition, these 
findings suggest that this development may well follow the same general phasal timetable in languages other than English and Hebrew, in spite of cross-linguistic differences in the structures employed to indicate causation.

The present paper approaches category development from the point of view of the acquisition of the causative in Inuktitut, an Eskimo language spoken in northern Canada, in order to determine whether the phasal development found for other languages also holds in a polysynthetic language of strikingly different typology to English and Hebrew. Inuktitut has two categories of verbs with respect to causatives: those permitting only morphological causatives, and those permitting both morphological and lexical (alternating) causatives, as described in more detail below. Spontaneous speech data is examined from eight Inuit children aged 1;0 through 3;6 learning Inuktitut as their first language. These data reveal three stages of causative acquisition of Inuktitut. In the first stage, children show no evidence of having categorized their verbs with respect to causative use: they produce no morphological causatives and produce lexical causatives with only a restricted set of frequent verbs, probably without understanding of their causative component. In the second stage, they use the causative morpheme only in a small number of structures involving imperative commands and first person optative suggestions. Omission of verb roots and/or verbal inflections, use of fixed forms, and some errors of morphological-causative use in situations in which a lexical causative would be expected suggest that children may be overusing the morphological causative at this stage with little regard for the verbs or verb categories in question. Lexical causatives show some evidence of becoming productive, but several verbless lexical causatives indicate remaining confusion in linking this structure with verb roots. In the third stage, children use morphological causatives in appropriate situations, while becoming more productive in appropriate use of lexical causatives. Examples of alternation between causative and noncausative utterances with the same verb root suggest that the children are paying more attention to the situations of use of the verbs in question. A period of lexical-causative overgeneralization errors in two children suggests that these children are at a stage of realizing that lexical causatives have a causative component, and that their development of two classes of verbs with respect to causatives is proceeding verb-by-verb. These data are consistent overall with the phasal view of development briefly outlined above. They suggest that the children first hypothesize that the morphological causative only serves as part of the imperative structure, often in unanalyzed amalgams, and that the lexical causative is a simple transitive without a causative component. Only once they achieve more adultlike use of these constructions do they show evidence of forming distinct categories of verbs with respect to causative formation.

\section{Causatives in Inuktitut}

Two primary linguistic resources are available to express causation in Inuktitut - one analytic and one lexical. In terms of analytic causative structures, Inuktitut exhibits a morphological causative but no periphrastic causative. An example is shown in (1), where the sentence in (1a) is a basic intransitive declarative and the sentence in (1b) is its causative counterpart. $^{2}$

(1) a. Piaraq qiajuq.

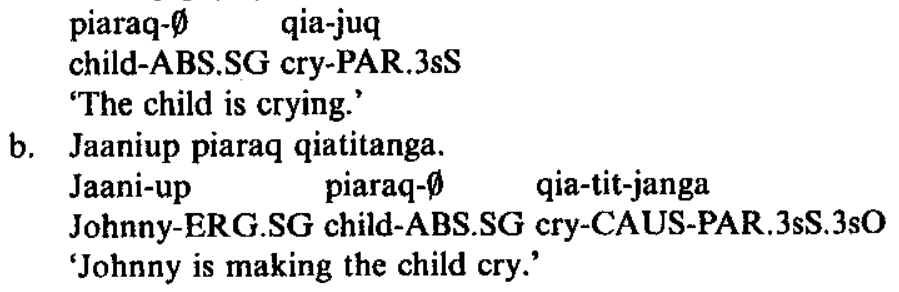

b. Jaaniup piaraq qiatitanga.

Jaani-up piaraq- $\emptyset$ qia-tit-janga
Johnny-ERG.SG child-ABS.SG cry-CAUS-PAR.3sS.3sO
'Johnny is making the child cry.'

In the causative version of the sentence, an overt causative morpheme is affixed to the verb, an agent of causation is added to the sentence, and the verbal inflection changes from intransitive to transitive.

In terms of lexical-causative structures, Inuktitut has an alternating causative but no suppletive form. An example is shown in (2). Again, the sentence in (2a) is a basic intransitive declarative and the sentence in (2b) is its causative counterpart.

(2) a. Puvirtajuuq qaartuq. puvirtajuuq- $\emptyset$ qaaq-juq balloon-ABS.SG burst-PAR.3sS

'The balloon burst.'

b. Puvirtajuuq qaartara. puvirtajuuq- $\emptyset$ qaaq-jara balloon-ABS.SG burst-PAR.1sS.3sO 'I burst the balloon.'

In the causative version of the sentence, the verb remains the same as in the noncausative sentence in that no causative morpheme is added. 
However, an agent of causation is added to the sentence (only visible in the inflection since Inuktitut does not allow first person pronouns in argument position), and the verbal inflection changes from intransitive to transitive.

As is the case with most languages, Inuktitut permits causatives of the morphological type with most if not all verbs. However, it allows only a subset of verbs to participate in the lexical-causative alternation. The distinction between the verbs that permit the lexical-causative alternation and those that do not is not yet clearly defined for Inuktitut. However, research to date indicates that the verbs permitting lexical-causative alternation include change-of-state verbs, verbs of grooming, some verbs of motion, verbs of putting, verbs of emission, and verbs of appearance. Those verbs forbidding lexical-causative alternation include at least some verbs of motion, and verbs of change of possession. Examples are in (3) and (4) respectively.

(3)

Jaaniup qainnguatanga inuujaq Jaani-up qai-nnguaq-jang inuujaq- $\emptyset$ Johnny-ERG.SG come-pretend-PAR.3sS.3sO doll-ABS.SG 'Johnny pretended to bring the doll.'

b. Sikituuq siqumigakku.

sikituuq- $\emptyset$ siqumi-gakku

skidoo-ABS.SG break-CSV.1sS.3sO

'I broke the skidoo.'

(4) a. Miajiup Jaani ijurtitanga (*... ijurtanga). Miaji-up Jaani- $\emptyset$ ijuq-tit-janga Mary-ERG.SG Johnny-ABS.SG laugh-CAUS-PAR.3sS.3sO 'Mary made Johnny laugh.'

b. Ilinniatitsijiup Miaji ullatitanga (*... ullatanga). ilinniatitsiji-up Miaji- $\emptyset$ ullak-tit-janga teacher-ERG.SG Mary-ABS.SG run-CAUS-PAR.3sS.3sO 'The teacher is making Mary run.'

As might be expected, most if not all verbs permitting the lexical-causative alternation in Inuktitut also permit use of a morphological causative. In these cases the morphological causative is used for indirect or permissive causation, where the lexical causative is used for direct causation. An example of this distinction is given in (5).

(5) a. Pirutsiaqauti kataqqaujara. pirutsiaqauti- $\emptyset$ katak-qqau-jara vase-ABS.SG fall-PAST-PAR.1sS.3sO

'I dropped the vase' (accidentally). b. Pirutsiaqauti katatiqqaujara. pirutsiaqauti- $\emptyset$ katak-tit-qqau-jara vase-ABS.SG fall-CAUS-PAST-PAR. $1 \mathrm{sS} .3 \mathrm{sO}$ 'I made the vase fall' (on purpose, e.g. by pushing it off the table).

Thus, there are two basic categories of verbs with respect to causatives in Inuktitut: those that take only a morphological causative, and those that take either a lexical or morphological causative depending on the semantics of the situation. The goal of the present study is to determine when and how Inuit children learn to categorize their verbs into these two classes.

\section{Methodology}

Data for this study are taken from two short-term longitudinal studies involving eight Inuit children aged 1;0 through 3;6 learning Inuktitut as their first language in two functionally monolingual Inuit communities in arctic Quebec. Two boys and two girls were included in each study, all free of any language or language-related difficulties. Children in both studies were videotaped with their friends and families in naturalistic communication situations including eating, playing, watching television (no sound), and a variety of caretaking situations. All taping took place during the children's normal daily activities, and little attempt was made to structure the sessions. Half the children lived in nuclear family homes (Lizzie, Louisa, Paul, Sarah) while the other half lived in multigenerational homes (Elijah, Jini, Lucasi, Tumasi).

Children in the first study were taped for five hours every four months for one year (Crago 1988), while children in the second study were taped four hours every month for nine months (Allen 1996). About half the data (2-2.5 hours per taping session) were then transcribed by native speakers. Information about the data is given in Table 1.

Data from all eight children were investigated for instances of lexical and morphological causatives. In addition, input data from tapes of the older set of children were investigated for instances of morphological causatives to assess the degree to which child use of morphological causatives reflected the input.

\section{Results}

Three main stages of causative use were found in the children studied, as indicated in Table 2. Children at stage one showed no evidence of 
Table 1. Data used

\begin{tabular}{llll}
\hline Child & Age & MLU at first taping & Source \\
\hline Elijah & $2 ; 0-2 ; 9$ & 2.5 & Alten 1996 \\
Jini & $1 ; 0-2 ; 0$ & 1.0 & Crago 1988 \\
Lizzic & $2 ; 6-3 ; 3$ & 2.8 & Allen 1996 \\
Louisa & $2 ; 10-3 ; 6$ & 2.0 & Allen 1996 \\
Lucasi & $1 ; 8-2 ; 8$ & 1.0 & Crago 1988 \\
Paul & $2 ; 6-3 ; 3$ & 2.5 & Allen 1996 \\
Sarah & $1 ; 4-2 ; 4$ & 1.0 & Crago 1988 \\
Tumasi & $1 ; 9-2 ; 9$ & 1.3 & Crago 1988 \\
\hline
\end{tabular}

Table 2. Stages of causative development

\begin{tabular}{lllllllll}
\hline Stage & Elijah & Jini & Lizzie & Louisa & Lucasi & Paul & Sarah & Tumasi \\
\hline One & & $1 ; 0 \cdot 2 ; 0$ & & & $1 ; 8-2 ; 8$ & & $1 ; 4-1 ; 8$ & $1 ; 9-2 ; 5$ \\
Two & $2 ; 0$ & & $2 ; 6-2 ; 7$ & $2 ; 10$ & & & $2 ; 0$ & $2 ; 9$ \\
Three & $2 ; 1-2 ; 9$ & & $2 ; 8-3 ; 3$ & $2 ; 11-3 ; 6$ & & $2 ; 6-3 ; 3$ & $2 ; 4$ & \\
\hline
\end{tabular}

knowledge of causation and did not use morphological causatives in their data. Children at stage two used morphological causatives only in imperative commands and first person optative suggestions, showed beginning evidence of productivity of lexical causatives, and demonstrated little regard for the verb root in question. Children at stage three used both morphological and lexical causatives in an adultlike way except for two children, Sarah and Louisa, who showed errors of lexical-causative overgeneralization during this period. Details of the findings are given below by stage.

\subsection{Stage one}

During the first stage, no morphological causatives were present at all. While a variety of lexical causatives were used, these were restricted to only a small number of verbs, and it is not clear that any causative meaning was intended by the children in using this construction. This stage includes all the data for Jini $(1 ; 0-2 ; 0)$ and Lucasi $(1 ; 8-2 ; 8)$, as well as the first two sessions for Sarah $(1 ; 4-1 ; 8)$ and the first three sessions for Tumasi $(1 ; 9-2 ; 5)$.

At the earliest part of this stage, all the children had a mean length of utterance in morphemes (MLU) of close to 1.0. Thus, utterances in which older children or adults would use causative constructions were expressed by only one morpheme, usually the verb root. For instance, Tumasi produced the bare verb root utterance in (6a) at $1 ; 9$ in a situation in which the wanted the door opened, but produced the more complete lexical causative in (6b) in a similar situation at $2 ; 5$.

(6)

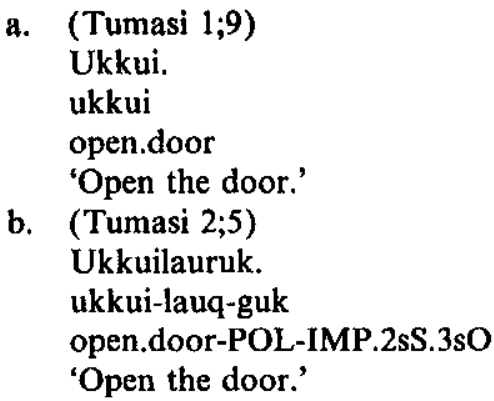

b. (Tumasi 2;5)

Ukkuilauruk.

ukkui-lauq-guk

open.door-POL-IMP.2sS.3sO

'Open the door.'

Similarly, Sarah produced the one-morpheme utterance in (7a) at 2;0 when asking to be dressed, while her mother responded using a full lexical-causative utterance, $(7 \mathrm{~b})$.

(7) a. (Sarah 2;0)

Apaa.

apaaq

clothe

'Clothe (me).'

(asking for help putting on her boot)

b. (Sarah's mother)

Apaalaurlagit.

apaaq-lauq-lagit

clothe-POL-IMP.1sS.2sO

'I'll clothe you.'

Occasionally children at this stage also use one-morpheme nominals in situations in which older children or adults may well use a lexicalcausative utterance. This is the case in (8a), where Lucasi represents a whole sentence by use of the direct object alone. A comparable adult utterance is given in ( $8 b)$.

(8) a. (Lucasi 2;4)

Savik.

savik

knife

'(Give me a) knife.' 
b. (Elijah's mother)

Saviguluit qailauruk.

savik-guluk-it qai-lauq-guk

knife-little-ABS.2Ssg come-POL-IMP.2sS.3sO

'Give me your little knife.'

The utterance in (8a) is not strictly correct with respect to adult language for the function it is trying to serve; when using only a nominal to request a knife in this context, adults would rather say savimmik (savik-mik/knifeMOD.SG) 'a/the knife'. Thus, Lucasi's utterance can be seen here as resulting from a strategy children use at this stage to linguistically represent a situation for which they do not have the full adult abilities.

One-morpheme utterances are also used in situations in which an older child or adult would normally use a morphological causative. This is particularly common in requests for food and drink. In the utterance in (9a), Sarah at 1;8 uses a one-morpheme request for tea, which Paul at 3;0 expresses with a morphological causative as in (9b). Note that although the phrase tituq- 'drink tea' constitutes two morphemes in adult language, it is most probably one fixed unit for children at this young age.

(9) a. (Sarah 1;8)

Tiituq.

tii-tuq

tea-consume

'Drink tea.'

b. (Paul 3;0)

Tiiturtilaunnga.

tii-tuq-tit-lauq-nnga

tea-consume-CAUS-POL-IMP.2sS.1sO

'Let me drink tea.'

Jini uses one of the few instances of a nonconsumption verb in this sort of construction, shown in (10a), as compared with a more complete utterance from Lizzie at an older age, in (10b). In the situation surrounding both these utterances, the girls are trying to get their mothers to help them tie dolls on their backs in blankets so that they can carry them in the traditional Inuit way.

$$
\begin{aligned}
\text { (10) a. } & (\text { Jini 1;4) } \\
& \text { Amaaq. } \\
& \text { amaaq } \\
& \text { carry.on.back } \\
& \text { ('Help me) carry (it) on my back.' }
\end{aligned}
$$

b. (Lizzie 2;8)

Amaartilaunnga.

amaaq-tit-lauq-nnga

carry on back-CAUS-POL-IMP.2sS.1sO

'Help me carry it on my back.'

Thus, Inuit children at the one-morpheme stage use only one morpheme to express themselves in utterances in which older children and adults might well use either morphological or lexical causatives.

Once children are able to put two morphemes together in an utterance, they do begin to use what look like adult lexical-causative constructions. These utterances are restricted to a small number of frequent verbs: aarqik- 'fix', annuraaq- 'clothe', katak- 'drop', naavik- 'empty', nungut'deplete', piiq- 'remove', qai- 'come', qimak- 'leave behind', ukkuaq- 'close door', and ukkui- 'open door'. These utterances are all imperative commands, as illustrated in (11), except for utterances from the most precocious of these four children (Tumasi), which include first person suggestions (12a) and some indicative utterances (12b).

(11) a. (Lucasi 2;8)

Piiruk.

piiq-guk remove-IMP.2sS.3sO

'Take it off.'

(asking his mother to take his sock off)

b. (Jini 1;4)

Qailauruk.

qai-lauq-guk

come-POL-IMP.2sS.3sO

'Give it (to me).'

(asking her mother to give her a bottle that has dropped on the floor)

(12) a. (Tumasi 2;1)

u-na nàavik-lagu

this.one-ABS.SG etripty-IMP.1sS.3sO

'Shall I empty this one?'

(threatening to emply a barrel of toy monkeys onto the floor)

b. (Tumasi 2;5;

Annuraarakkit.

annuraaq-gakirit

clothe-CSV.1 $\mathrm{sS} .2 \mathrm{sO}$

'I'll dress youl.'

(doing up the buttons on his grandfather's shirt) 
However, it is not clear that children at this stage understand the causative nature of these constructions.

No morphological causatives appear at this stage. In addition to the one-morpheme utterances, which persist into the two-morpheme period, children also use alternative formulations of utterances in which a morphological-causative form might be used at an older age. Lucasi at $2 ; 8$ is feeding a puppy on the floor. His mother is not at all happy about this situation and says the utterance in (13a) with a morphological causative. Lucasi responds with the utterance in (13b) rather than with a morphological causative such as (13c).

(13) a. (Lucasi's mother)

Apaapatinagu!

apaapa-tit-nagu

eat-CAUS-ICM.NEG.XxS.3sO

'Don't feed it!'

b. (Lucasi 2;8)

Apaapali.

apaapa-li

eat-IMP.3sS

'Let it eat.'

c. (hypothetical response)

Apaapatigumagakku.

apaapa-tit-guma-gakku

eat-CAUS-want-CSV. $1 \mathrm{sS} .3 \mathrm{sO}$

'I want to feed it.'

A similar situation arises when Tumasi at 2;1 wants to have a bottle. He uses the truncated passive construction in (14a) instead of using the morphological-causative construction common at older ages, (14b), illustrated here by a command from Lizzie's mother to make Lizzie give a bottle to her doll.

(14) a. (Tumasi 2;1)

Amaamaliurtau. [ $=$ amaamaliurtaugumavunga]

amaama-liuq-jau [-guma-vunga]

bottle-make-PASS [-want-IND.1sS]

'(I want to be made a bottle.'

b. (Lizzie's mother)

Amaamatinngualiruk.

amaama-tit-nnguaq-liq-guk

suckle-CAUS-pretend-POL-IMP.2sS.3sO

'Pretend to make it drink milk (from a bottle).'
Note that both the utterances in (13p) and (14a) are grammatical and appropriate in these situations. The point here, however, is that the children are using such utterances in situations in which morphological causatives could be used and are used at older ages. Obviously different discourse situations require different formulations of the same idea. However, these examples are meant to illustrate that children at this stage never use morphological causatives even though they do encounter discourse situations in which they would be appropriate.

Two hypotheses are possible to explain the lack of morphological causatives at this stage. First, children may assume all verbs take lexical causatives, and thus that no morphological causatives are necessary. However, this would predict an abundance of utterances in which use of lexical causatives was overgeneralized to those verbs that require morphological causatives in Inuktitut. Since this is not the case, a second hypothesis seems more plausible: that children have not yet discovered causation as a cognitive concept at this stage and thus are not intending to express causation at all. Lexical causatives at this stage would then be instances of simple transitive verbs for these children. Such reasoning would be consistent with Bowerman's (1974) observation for English that children use lexical causatives from the earliest ages but only show evidence of the concept of causation from the time of first use of morphological causatives. At this stage, then, it is most likely that children have not categorized their verbs in any way with respect to causation. In terms of the phasal view of development set out in the introduction, children are clearly still in the first rote knowledge phase in using causative forms.

\subsection{Stage two}

The first uses of morphological causatives occur during stage two, sometime between $2 ; 0$ and $2 ; 10 \mathrm{cr}$ so depending on the child. These uses are all either imperative commaids or optative first person suggestions and show little regard for the verb in question. Lexical causatives also occur, still in appropriate contexts itough occasionally in verbless structures. This stage includes the first scsitions for Elijah $(2 ; 0)$ and Louisa $(2 ; 10)$, the first two sessions for Lizit $(2 ; 6-2 ; 7)$, the third session for Sarah $(2 ; 0)$, and the fourth session fo: Tumasi $(2 ; 9)$. Three patterns are typical of morphological causatives $d u$ ing this stage: use of a verb root and causative morpheme without a proper verbal inflection, use of a causative morpheme and verbal inflection without a verb root, and use of a verb root and fixed form of causitive morpheme plus inflection. These are 
each explicated below, as well as structures typical of lexical causatives at this stage.

4.2.1. Morphological causatives with no inflection. The first pattern, use of a verb root plus causative morpheme without a verbal inflection, is found in utterances from Sarah $(2 ; 0)$ and Lizzie $(2 ; 7)$. This type of utterance may indicate that the children have figured out that the causative morpheme may be part of the utterance but haven't yet figured out how this affects the argument structure of the verb, and thus leave off the inflection since they aren't sure which inflection to use.

The example in (15) clearly illustrates the tentative status of causative use at this stage. Sarah's mother has just offered her something to drink and has brought out a plate of cookies. Sarah would also like to have refreshments offered to the researcher who is present in the room but cannot do it herself. The following conversation ensues.

(15) (Sarah 2;0)

Sarah: Tiituq

tii-tuq

tea-consume

'Have tea.'

Mother: Haa?

'What?'

Sarah: Una

'This one' (pointing to the researcher).

Mother: Suna

'What?'

Sarah: Tiiturtilau.

tii-tuq-tit-lauq

tea-consume-CAUS-POL

'Let (her) have tea.'

Mother: Tiiturtilaurlagu?

tii-tuq-tit-lauq-lagu

tea-consume-CAUS-POL-IMP.1sS.3sO

'Shall I let her have tea?'

Sarah: Aaa.

'Yes.'

It is clear that Sarah knows what she wants but is having some difficulty expressing it linguistically.

Lizzie produces a similar utterance at $2 ; 7$, though it has no verb root. She wants her cousin to help her fold laundry and says the utterance in (16).
(16) (Lizzie 2;7)

Tilau.

tit-lauq

CAUS-POL

'Make it.'

This is perhaps the most minimal causative utterance possible, with just the causative morpheme and the politeness affix that normally precedes an imperative inflection. Since all Lizzie's causative utterances to this point are produced with imperative inflections and contain the politeness affix-lauq-, it is likely that she has misanalyzed -tilauq-as one morpheme, and thus in (16) she is producing what she believes to be just the causative morpheme.

Other morphological-causative utterances without inflections are produced by Lizzie $(2 ; 8,3 ; 2)$ and Louisa $(3 ; 0,3 ; 3)$ at later ages, though they are not the only morphological-causative forms produced at those ages. These sorts of utterances are not produced at all by Elijah, Paul, or Tumasi in the data analyzed.

4.2.2. Morphological causatives with no verb. A second pattern in the initial stages of use of the morphological causative involves producing the causative morpheme and verbal inflection without a verb root. Examples are given below.

Lizzie uses the causative morpheme some 15 times at 2;6 and 11 times at $2 ; 7$, all in imperative and optative utterances with no verb root. A complete set of the utterances and their contexts is given in (17) below (some occur more than once in the same situation). Note that the superscript letters following each description indicate whether a morphological causative $\left({ }^{a}\right)$ or a lexical causative $\left(^{b}\right)$ would be preferred in adult language, on the basis of an assessment of the relevant videotape portion by an Inuktitut language consultant.

(17) a. (Lizzie 2;6, 2;7)

Tilauruk.

tit-lauq-guk

CAUS-POL-IMP.2sS.3sO

'Make it do X'.

(telling mother or father to put back a photo album, make

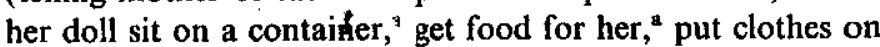
her doll," blow up a balloon " stick a balloon on the ceiling," put in her barrette, beaid ier doll's hair, ${ }^{b}$ remove sealskin boots, ${ }^{b}$ put a hair extensicx. on her doll, ${ }^{b}$ pick up a fallen pen $^{b}$ ) 
b. (Lizzie 2;6)

Tilaukkit.

tit-lauq-kkit

CAUS-POL-IMP.2sS.3po

'Make them do X.'

(telling her father to put back a photo album," telling her mother to increase the volume on the television ${ }^{b}$ )

c. (Lizzie 2;7)

Tilaunnga.

tit-lauq-nnga

CAUS-POL-IMP.2sS.1sO

'Make me do X'

(telling her cousin to color a picture for her ${ }^{\mathrm{a}}$ )

d. (Lizzie 2;6)

Tilaurta.

tit-lauq-ta

CAUS-POL-IMP.1pS

'Shall we make it do $X$ ?'

(suggesting to her mother to resume playing a question-andanswer game ${ }^{\mathrm{b}}$ )

e. (Lizzie $2 ; 6,2 ; 7)$

Tilaurlagu.

tit-lauq-lagu

CAUS-POL-IMP.1sS.3sO

'Shall I make it do X?'

(suggesting that she takes the slippers out of her father's sealskin boots, ${ }^{\mathrm{a}, \mathrm{b}}$ put on a Cinderella video, ${ }^{\mathrm{a}, \mathrm{b}}$ untie a balloon $^{\mathrm{a}, \mathrm{b}}$ )

f. (Lizzie 2;7)

Tilaurlagit

tit-lauq-lagit

CAUS-POL-IMP.1sS.2sO

'Shall I make you do X?'

(suggesting that she rub a balloon on her mother's hair, ${ }^{\text {a let }}$ her sister play with some clothes ${ }^{\mathrm{a}}$ )

The intended verb for several of Lizzie's verbless utterances has been modelled in previous utterances by her conversational partners. The conversation in (18) is one instance in which the verb in question takes a morphological causative in adult speech.
(18) (Lizzie 2;6)

Mother: Una itsivatinngualugu itsivautannguanut.

u-na itsiva-tit-nnguaq-lugu

this.one-ABS.SG sit-CAUS-pretend-ICM.XxS.3sO

itsivautaq-nnguaq-nut

chair-toy-ALL.PL

'Pretend to make this one sit on the toy chairs.'

Lizzie: Itsivautannguanut?

itsivautaq-nnguaq-nut

chair-toy-ALL.PL

'On the toy chairs?'

Mother: Aaa.

'Yes.'

(Lizzie tries to seat the doll without success)

Lizzie Tilauruk!

tit-lauq-guk

CAUS-POL-IMP.2sS.3sO

'You make it (sit)!'

However, in the situation in (19), the verb in question normally takes a lexical causative.

(19) (Lizzie 2;6)

Father: Kamikka pilaukkik.

kamik-kka piiq-lauq-kkik

sealskin.boot-ERG.1Sdu remove-POL-IMP.2sS.3dS

'Take off my sealskin boots.'

Mother: Piilaukkiguuq panitk.

piiq-lauq-kkik-guuq' panik

remove-POL-IMP.2sS.3dS-RSP daughter

'He said to take them off, daughter.'

Lizzie: Tilauruk.
-lauq-guk
CAUS-POL-IMP.2sS.3sO
'You make it (come of $)$ ' [ = you take it off $]$.

In this situation the lexical causative piiy- 'remove' was modelled by both parents in the preceding utterances, and yet Lizzie chose to use a morphological causative without a verb root. '

In another situation, Lizzie hersel produces a lexical causative in conjunction with the verbless morphological causative, as shown in (20). Here she is trying to get her mother to fix a barrette in a doll's hair. 
(20) (Lizzie 2;6)

Lizzie: Tilauruguna.

tit-lauq-guk-u-ng

CAUS-POL-IMP.2sS.3sO-this.one-ABS.SG

'Make this (be fixed).'

Lizzie: Tilauruk.

tit-lauq-guk

CAUS-POL-IMP.2sS.3sO

'What?'

Lizzie: Una aarqilauruk.
u-na
aarqik-lauq-guk
his.one-ABS.SG fix-POL-IMP.2sS.3sO
'Fix this.'

The same sort of situation occurs in example (21).

(21) (Lizzie 2;7)

Lizzie: Qailauruk una.

qai-lauq-guk

come-POL-IMP.2sS.3sO this.one-ABS.SG

'Give this (to me).'

(wants her father to pick up a pen from the floor)

Father: Tiguliruk.

tigu-liq-guk

take-POL-IMP.2sS.3sO

'Take it.'

(he tells her to get it herself)

Lizzie: Siaru.

'Later.'

Lizzie: Tilauruk!

tit-lauq-guk

CAUS-POL-IMP.2sS.3sO

'You make it (come)' [= give it to me]!

(she commands again; he finally picks it up)

All three of the lexical causative verb roots represented in these latter examples ( piiq- 'remove', aarqik- 'fix', qai- 'come') are quite common in child language, and Lizzie uses each of them in both transitive (lexicalcausative) and intransitive utterances at these ages. The utterances in (19) through (21), then, suggest that she is not yet sure which verb roots go with which type of causative structure, even in the face of the lexical causatives she is already using correctly, and also that she probably does not yet realize that the lexical-causative construction is actually causative. Many of her verbless morphological causatives are quite emphatic and are often used when a previous request for something has been denied, as in (20) and (21) above, suggesting that she may consider the causative morpheme to be an emphasis marker at this stage.

Tumasi at $2 ; 9$ produces only one example of the morphological causative, which is of the same form as those above from Lizzie. In the example in (22), he illustrates that he knows the verb he is talking about but doesn't use it in his causative utterances. He is attempting to rollerskate. His aunt has been helping him but gets tired and stops supporting him. He strides out on his own, and the following conversation ensues.

(22) (Tumasi 2;9)

\begin{tabular}{|c|c|}
\hline Tumasi: & $\begin{array}{l}\text { Siarajaattunga [= siarrijaartunga]. } \\
\text { siarri-jaaq-junga } \\
\text { skate-REP-PAR.1sS } \\
\text { 'I'm skating.' } \\
\text { (skates on his own) }\end{array}$ \\
\hline Grandma: & $\begin{array}{l}\text { Aannilangaliravit. } \\
\text { aanniq-langa-liq-gavit } \\
\text { hurt-FUT-PRES-CSV.2sS } \\
\text { 'You're going to hurt yourself.' } \\
\text { (he has fallen backwards) }\end{array}$ \\
\hline Tumasi: & $\begin{array}{l}\text { Aana, tilaunnga. } \\
\text { Aana tit-lauq-nnga } \\
\text { Anna CAUS-POL-IMP.2sS.1sO } \\
\text { 'Anna, help me (skate).' }\end{array}$ \\
\hline Aunt: & $\begin{array}{l}\text { Asuguuq, gunnairit. } \\
\text { asuguuq gunnaiq-git } \\
\text { okay no.longer-IMP.2sS } \\
\text { 'Come on, you've had enough.' }\end{array}$ \\
\hline Tumasi: & $\begin{array}{l}\text { Tilinnga, atii. } \\
\text { tit-liq-nnga } \\
\text { CAUS-POL-IMP.2sS.1sO come.on } \\
\text { 'Come on, help me (skate).' }\end{array}$ \\
\hline
\end{tabular}

He clearly knows the correct verb root since he has just used it in the preceding utterance. However, in the causa ive utterance, he chooses not to use the verb root. Note that this verb root would appear with a morphological causative in adult language in the above situation.

Finally, Louisa produces one such utterance in her data at $2 ; 10$. She says (23b) in response to her mother's question in (23a), asking if the mother should dial the phone for Louisa. 
(23) a. (Louisa's mother)

Tilaurlagiit?

tit-lauq-lagit

CAUS-POL-IMP.1sS.2sO

'Shall I help you?'

b. (Louisa $2 ; 10$ )

Tilaunnga.

tit-lauq-nnga

CAUS-POL-IMP.2sS.1sO

'Help me.'

Since adults do occasionally produce verbless morphological-causative structures, as in (23a) and (40b), they cannot always be considered ungrammatical in the speech of the child. The children (like the adults) may just be eliding the verb as a discourse strategy since the action they are talking about is already understood, in the same way they elide subjects and objects that represent referents that are already known (Allen and Schröder i.p.). However, the fact that two of the children (Lizzie, Tumasi) produce only these verbless structures in their first taping sessions that include morphological causatives, including several instances in which lexical causatives would be required in adult language, suggests that this pattern has different significance for children at this stage than it does for adults. The children may, in fact, be eliding the verb as a syntactic strategy since they are not sure how to combine the linguistic expression of causation with the verb at hand. The pervasiveness of verb elision, especially in data from Lizzie, makes this latter possibility the more tempting explanation.

Verbless morphological causatives appear sporadically in the data from all four older children even after this stage, though they are no longer the sole form of morphological causatives. The frequency of appearance of verbless morphological causatives after this stage may well have something to do with the input that the children received. For example, Lizzie's parents produce the most morphological-causative utterances without verb roots of the four sets of parents whose input was examined, and Lizzie also produced the most such utterances of all the eight children after this period in which they were her only morphological-causative utterances. Elijah's parents, on the other hand, produced only one morphological causative without a verb root in the entire data set, and Elijah produced only two such utterances in his data.

4.2.3. Fixed-form morphological causatives. The third pattern of early morphological-causative use involves a verb root plus a fixed form of the causative morpheme plus imperative inflection. This pattern is especially apparent in data from Elijah at $2 ; 0$, since 11 of his 13 morphologicalcausative utterances at that age are of the form: verb root +-tilaunnga 'make me do X', Examples are given in (24).

(24) (Elijah 2;0)

a. Takutilaunnga.

taku-tit-lauq-nnga

see-CAUS-POL-IMP.2sS.1sO

'Help me see.'

(wanting to be lifted up to the window to see outside, wanting to see his father)

b. Ataatamuurtilaunnga.

ataata-mut-uq-tit-lauq-nnga

father-ALL.SG-go-CAUS-POL-IMP.2sS.1sO

'Let me go to father.'

(wanting to be taken to join his father who is outside)

c. Sikituurtilaunnga.

sikituuq-tit-lauq-nnga

ride.skidoo-CAUS-POL-IMP.2sS.1sO

'Let me ride the skidoo.'

(wanting to have a ride on the skidoo)

d. Ikittilaunnga.

ikit-tit-lauq-nnga

ignite-CAUS-POL-IMP.2sS.1sO

'Help me turn the light on.'

(wanting his mother to take him to the light switch so he can turn on the light)

e. Piirtilaunnga.

piiq-tit-lauq-nnga remove-CAUS-POL-IMP.2sS.1sO

'Let me get off.'

(wanting his sister to let him down)

f. Paunngatilaunnga.

pa-unnga-aq-tit-lauq-nnga

up.there-ALL-go-CAUS-POL-IMP.2sS.1sO

'Let me go up there.'

(wanting to follow his sister up to the place on the hill where she's playing)

Note that Elijah produced several examples of the type in (24b), asking to visit different people. Some of these had clear pauses between the first portion of the word and the morpheme group -tilaunnga, suggesting that 
Elijah was treating -tillaunnga as a separate unit from the verb, and thus strengthening the impression that this morpheme group is a fixed form for him at this stage. At any rate, all six of the examples in (24) are grammatical with respect to adult language.

Elijah also produced one example of a causative morpheme using the fixed form -tilaunnga on a verb with which his mother had just modelled a lexical causative. Clothing verbs in Inuktitut typically take lexical causatives, as seen in (7) and (12b) above. However, a few of these, such as paampu- 'wear diaper' below, can take either a lexical or a morphological causative with only small differences in meaning. The fact that Elijah says the utterance in (25b) with a morphological causative even though his mother has just used this verb in a lexical-causative construction, (25a), is another indication that -tilaunnga may be a fixed imperative form for him at this stage.

(25) a. (Elijah's mother)

Paampulaurlagiit?

paampu-lauq-lagit

wear.diaper-POL-IMP.1sS. $2 \mathrm{sO}$

'Shall I put your diaper on?' [lit. 'Shall I diaper you?']

b. (Elijah 2;0)

Paamputilaunnga.

paampu-tit-lauq-nnga

wear.diaper-CAUS-POL-IMP.2sS.1sO

'Put my diaper on.' [lit. 'Make me wear a diaper.']

The second form using the causative morpheme produced by Elijah at this stage is the optative -tilagu; it is used in the remaining two of his 13 morphological causative utterances as shown in (26).

(26) (Elijah 2;0)

Takutilagu.

taku-tit-lagu

see-CAUS-IMP.I IsS.3sO

'Let me see it.'

(wanting his mother to go with him to watch the dog urinate in the patio, to look out the window)

The presence of an alternative inflection with the causative morpheme casts some doubt on the hypothesis that Elijah has a fixed causative form at this stage. However, note that the second form is only used with one verb, which is one of the most frequent verbs in Elijah's speech at this age.

In summary, all of the utterances produced by Elijah at this stage are grammatical with respect to adult language. However, the predominance of one form at this stage indicates that Elijah's use of the morphological causative is not as productive as in adult language, and therefore that his utterances may result from a different pattern than adult utterances of the same type.

4.2.4. Lexical causatives. The question remains how lexical causatives fit into this pattern. All the children at this stage produce lexical causatives with a range of verb roots and sentence types. Since all the morphological causatives at this stage appear with imperative or optative inflections, it is interesting to note that lexical causatives also appear with these inflections, and thus that it is not the case that all commands are expressed with morphological causatives. Four of the five children produce lexical causatives with imperative inflections with the verb root qai- 'come', two with aarqik- 'fix', and one each with piiq- 'remove' and turqutuq- 'place inside'. Imperatives are also used with noncausative transitives at this age, with one child each using imperative inflections on atuq- 'use', aittuq'give', and taku- 'see'. Finally, four of the children use imperative inflections without verb roots, producing utterances that look like verbless lexical causatives, such as those in (27). Note that the superscript letters following each description indicate whether a morphological causative $\left({ }^{a}\right)$ or a lexical causative $\left({ }^{b}\right)$ would be preferred in adult language, on the basis of an assessment of the relevant videotape portion by an Inuktitut language consultant.

(27) a. (Elijah 2;0, Sarah 2;0)

Lauruk.

lauq-guk

POL-IMP.2sS.3sO

'Do it.'

(asking his sister to put a soft drink into his pocket, ${ }^{b}$ asking her father to put a piece of paper in the garbage ${ }^{b}$

b. (Lizzie 2;6, Louisa 2;10)

Launnga.

lauq-nnga

POL-IMP.2sS.1sO

'Let me.'

(asking her mother to give her some food of the same kind that her sister has," asking her sister to curl her hair with a curling iron ${ }^{\text {b) }}$

Some of these verbless seemingly lexical-causative utterances are used in similar situations to those in which stage-two verbless morphological causatives are used; indicating once again the insecurity of the children 
at this stage with both the use of the linguistic expression of causation and the use of causatives with verb roots in general.

However, there is also some indication that lexical causatives are beginning to be productive for children at this stage. A few instances of alternation between causative and noncausative utterances with the same verb root suggest that children are beginning to be able to manipulate sentence structures and that they understand that certain verbs may have a causative component. Examples are given in (28) and (29). During the utterances in (28), Lizzie is sitting on the floor in her playroom with her mother and sister playing with dolls. Using the intransitive noncausative form of the verb root ukkuaq- 'close', she asks her mother if the door should be closed. Her mother tells her not to close the door using a lexical-causative utterance, to which Lizzie responds with the transitive causative form of the verb while closing the door.

(28) (Lizzie 2;6)

$\begin{array}{ll}\text { Lizzie: } & \text { Una ukkuali? } \\ & \text { u-na } \\ \text { this.one-ABS-SG close-IMP.3sS } \\ \text { 'Shall this one close?' } \\ \text { Mother: } & \text { Auka, ukkuarunnailugu. } \\ & \text { auka ukkuaq-gunnaiq-lugu } \\ & \text { no close-no.longer-ICM.XxS.3sO } \\ \text { 'No, don't close it.' } & \\ \text { Lizzie: } & \text { Una ukkualangajara. } \\ & \text { u-na ukkuaq-langa-jara } \\ \text { this.one-ABS.SG close-FUT-PAR.1sS.3sO } \\ \text { 'I'm closing this one.' }\end{array}$

The next set of utterances centers around the verb root qai- 'come, get, bring'. This is a common verb root across all the children, especially with imperative inflections, and is used by all the children in both intransitive and lexical-causative frames. The following utterances, though not used consecutively or referring to the same referents, are used within an hour of each other in the same general situation. In (29a), Elijah is standing by the window looking out and asks his mother to come and join him using the intransitive noncausative form of qai-. In (29b), Elijah is wanting to play with a ball and tells his mother, using the transitive causative form of qai-, that he wants to get the hockey stick in order to do so. In (29c), Elijah's mother is eating some potato chips and he wants to have some too so asks her to give him some, using the antipassive version of the transitive causative form of the verb root.
(29) (Elijah 2;0)

a. Qaigit.

qai-git

come-IMP.2sS

'Come here.'

b. Haakirutialu silamiittuq qaigumajara.

haakiruti-aluk- $\emptyset$ sila-mi-it-juq

hockey.stick-EMPH-ABS.SG outside-LOC-be-PAR.3sS

qai-guma-jara

come-want-PAR.1sS.3sO

'I want to get [ $=$ make come] the hockey stick that is outside.'

c. Qaitsigit anaana.

qai-tsi-git anaana

come-ATP-IMP.2sS mother

'Give me some [= make some come to me], mother.'

The evidence in section 4.2 .4 suggests that Inuit children at this stage are in a state of confusion over lexical causatives. On one hand, they show some understanding of the causative component of lexical causatives in examples of alternation. On the other hand, they use both lexical and morphological verbless causative structures to express desired causation, often in the same situation, and often in situations in which the intended verb would require the other form. These data indicate that children certainly do not have a complete understanding of how to use causatives at this stage, nor of which verbs go with which causative types.

4.2.5. Discussion. The three types of morphological-causative forms characterizing stage two - no inflection, no verb root, and fixed form indicate that the morphological causative is not being used in an entirely adultlike way at this stage. Though all these sorts of utterances appear in adult data and thus cannot be termed ungrammatical, their pervasiveness at this stage indicates a diversion from typical adultlike use of the morphological causative.

One pattern emerging from data at this stage is that the morphological causatives of these children show more relationship to imperative and first person optative inflections than they do to verb roots in general. In fact, the utterances in each of the three typical forms at this stage are all either commands or first person suggestions; morphological causatives do not appear at this stage with declaratives, interrogatives, or other sentence types. This suggests that the children may initially begin using the causative morpheme with the hypothesis that this morpheme is only a required part of the form to be used when you wish to command 
someone to make someone or something else do something for you, and that it has relatively little to do with their understanding of the linguistic representation of causation per se, or of the division of verb roots into two categories with respect to causatives. The clear agency of commands and first person suggestions may then serve as the initial trigger for the children's linguistic expression of causation.

The presence of imperative inflections with lexical causatives makes it clear that not all commands and suggestions use the morphological causative at this stage, and productivity data indicate that children are beginning to realize the causative component of lexical causatives. However, the majority of the data, and especially the causatives without verb roots, indicates confusion between morphological and lexical causatives. Thus, the data in this section suggest that little if any division of verb roots into categories with respect to linguistic representation of causation has yet taken place at stage two. While lexical causatives are used in an adultlike way with a variety of verbs and inflections, morphological causatives appear in three nontypical (though not ungrammatical in colloquial adult speech) forms that indicate little attention to verb roots or their categorization. Early morphological causatives are rather linked strongly with command and first person suggestion situations. In terms of the phasal view of development set out in the introduction, children at this stage are still in the rote knowledge phase with respect to morphological causatives since they use only unanalyzed forms. With respect to lexical causatives, they seem to be moving into the second early modifications phase, since lexical causatives show some evidence of early learning on an individual verb-by-verb basis.

\subsection{Stage three}

In the third stage of causative acquisition, Inuit children begin to use causatives in a more adultlike way. Morphological causatives are used for the most part with the proper verb roots and inflections, and in a variety of forms including declaratives and interrogatives. Lexical causatives are used with a larger variety of verbs than in the previous stage. Alternations between causative and noncausative utterances with the same verb root indicate that the children are beginning to master the linguistic expression of causation. Finally, lexical-causative overgeneralizations in two children suggest their realization that lexical causatives have a causative component, and that the appropriate causative type for each verb root is learned on a verb-by-verb basis.
4.3.1. Morphological causatives. After a period of morphological-causative use in stage two that illustrates some confusion over the relationship between causatives and verbs, children in stage three begin to use the causative morphology in a more adultlike way, and without the patterns typical of stage two. Though children still use the morphological causative with an imperative inflection in several instances, other inflections begin to appear with causatives, including indicative and interrogative. By the last session for each of the four oldest children, however, morphological causatives are no longer used in any commands. This is rather unusual in comparison with adult data since morphological causatives often appear with imperative inflections in adult language. Examples are shown in (30).

(30) a. (Lizzie 2;10)

Una silamuurtisijara.

u-na

this.one-ABS-SG

sila-mut-uq-tit-si-jara

outside-ALL-go-CAUS-PRES-PAR.1sS.3sO

'I'll make this one go outside.'

(planning to take her doll outside on a toy honda)

b. (Paul 3;3)

Paniik itsivatitait.

panik itsivaq-tit-jait

daughter sit-CAUS-PAR.2sS.3sO

'Daughter, you made it sit.'

(telling his playmate that she made a doll sit down)

c. (Elijah 2;5)

Taimailuurunnailunga akkimi takutilaaraminga? ${ }^{3}$

ta-imaak-iluuq-gunnaiq-lunga akki-mik

ANA-thus-do-no.longer-ICM.1sS fish.hook-MOD.SG

taku-tit-laaq-gaminga

see-CAUS-FUT-CSV.4sS. $1 \mathrm{sO}$

'If I don't do this, will he [=you] let me see the fish hook?' (negotiating with his cousin who wants him to stop banging the table)

Alternation between noncausative and causative uses of the same verb root provides some evidence for productivity of the morphological causative. Several examples of this occur within the data, both within the utterances of one speaker, arc across two speakers. Two examples from Louisa and one from Elijah show causative/noncausative alternation within the same speaker. In (31), Louisa is playing with a toy car, pushing 
it down a mini hill in the carpet and trying to make it go underneath a slightly raised extension cord. After one successful attempt she utters (31a), and after another she utters (31b).

(31) (Louisa 3;6)

a. Ataanuurtitara. ${ }^{4}$

ata-nganut-uq-tit-jara

under-ALL.3Ssg-go-CAUS-PAR.1sS.3sO

'I made it go to underneath.'

b. Ataanuurtuq.

ata-nganut-uq-juq

under-ALL.3Ssg-go-PAR.3sS

'It went to underneath.'

In (32), Louisa and her cousin are playing with dolls. Louisa is afraid that she has banged the head of one of the dolls and asks her cousin (32a) and then (32b).

(32) (Louisa 3;6)

a. Niarquavaa?

niarquaq-va

bump.head-INT.3sS

'Did it bump its head?'

b. Niarquatitara?

niarquaq-tit-jara

bump.head-make-PAR.1sS.3sO

'Did I make it bump its head?'

In example (33), Elijah is telling his mother about putting his knife in a crack in the floor of the shack in the summer camp. He first says (33a) and then (33b).

(33) (Elijah 2;5)

a. Killimuurtuvinialuguna.

killi-mut-uq-juq-viniq-aluk-u-na

crack-ALL.SG-go-NOM-former-EMPH-this.one-ABS.SG

'This one went in the crack.'

b. Killimuurtikainnatara.

killi-mut-uq-tit-kainnaq-jara

crack-ALL.SG-go-CAUS-PAST-PAR.1sS.3sO

'I made it go in the crack.'

In addition, one example from Elijah shows causative/noncausative alternation across two speakers. In (34), Elijah is rocking back and forth on a chair beside a table. His mother is trying to get him to stop rocking and says (34a), intimating that if he keeps rocking on the chair, the chair will fall against the table and Elijah will bang his teeth. Elijah mischievously responds with (34b).

(34) a. (Elijah's mother)

Kigutialutit kililangamimmata ... itsivautaalu urrupat.

kiiguti-aluk-tit kili-langa-mi-mmata

tooth-EMPH-ABS.2Spl bleed-FUT-also-CSV.3pS

itsivautaq-aluk- $\emptyset$ urru-ppat

chair-EMPH-ABS.SG fall-CND.3sS

'Your teeth will bleed ... if the chair falls.'

b. (Elijah 2;5)

Urrutillagu?

urru-tit-lagu

fall-CAUS-IMP.1sS.3sO

'Shall I let it fall?'

These examples suggest that the children have properly segmented the causative morpheme by this point, have understood its causation component, and are using the morpheme productively.

4.3.2. Lexical causatives. Lexical-causative constructions are also used in adultlike ways at this stage, as shown in the examples in (35).

(35) a. (Paul 2;6)

Matulaurlaguruna?

matuq-lauq-lagu-u-na

cover-POL-IMP.1sS.3sO-this.one-ABS.SG

'Shall I cover this one?'

(offering to close the closet door)

b. (Elijah 2;9)

Qupirrualunni naaviijualu!

qupirruq-aluk-nik naavik-i-juq-aluk insect-EMPH-MOD.PL empty-ATP-PAR.3sS-EMPH

'He spilled insects!'

(a character on a children's television show has emptied some insects from a jar)

c. (Elijah 2;5)

Taatsuminga nakailangajunga.

ta-u-minga

nakat-i-langa-junga

ANA-this.one-MOD.SG cut-ATP-FUT-PAR.1sS

'I'm going to cut this one.'

(planning to cut some food on the table) 
d. (Lizzie 2;10)

Una qilalaurlagu imaak?
u-na
qilak-lauq-lagu
imaak

this.one-ABS.SG tie-POL-IMP.1sS.3sO thus

'Shall I tie this one like this?'

(tying a piece of thread)

e. (Louisa 3;2)

Una qimattara.

u-na qimak-jara

this.one-ABS.SG leave.behind-PAR.1sS.3sO

'I left this one behind.'

(missing out one stuffed toy when she takes all the others to another room)

Again, alternations between transitive causative and intransitive noncausative uses of the same verb root in sequence and/or in similar contexts suggest productivity in the use of lexical causatives. Some examples of this alternation are given in (36) through (38). The utterances in (36) focus on the verb root piiq- 'remove', which is very common in the speech of all the children in both transitive causative and intransitive noncausative forms. The examples given here occur within five minutes of each other though they do not refer to the same context. In (36a) Louisa uses piiq - in its intransitive noncausative form, noting that her attempts to pull a piece of paper out of the bottom of a wagon will not be successful. In (36b) she is taking off a small cap she has been wearing, using the antipassive form of the lexical causative for this verb root.

(36) (Louisa $3 ; 2$ )

a. Pjinianngituq

piiq-niaq-nngit-juq

remove-FUT-NEG-PAR.3s

'It won't come off.'

b. Piilirqunga mikijurulummik.

piiq- $\emptyset$-liq-vunga miki-juq-guluk-mik

remove-ATP-PRES-IND.1sS be.small-NOM-DIM-MOD.SG

'I'm taking off the small one,'

In the next sequence, Paul is sitting with his legs under the edge of a carpet, running a toy car down the resulting rise and trying to make it go down and under a bridge created by an extension cord without having the car crash or turn over. He uses the verb root sukkuq- 'break' for any disastrous result happening to the car, announcing to his playmates that the car either did or didn't smash or get overturned during each attempt.
During the half-hour duration of this interaction, he utters sentences like that in (37a), using the intransitive noncausative form of this verb, many times in both the affirmative and negative with a variety of inflections. In the middle of the interaction he says (37b), using the transitive causative form of the verb.

(37) (Paul 3;3)

a. Sukkungitturulu.

sukkuq-nngit-juq-guluk

break-NEG-PAR.3sS-DIM

'It didn't break.'

b. Sukkuqara.

sukkuq-vara

break-IND. $1 \mathrm{sS} .3 \mathrm{sO}$

'I broke it.'

In the final set of utterances Elijah uses the verb root aarqik- 'fix', another common verb root across the four children. In the first three of these utterances, Elijah is talking about a small toy organ that he has recently received. Several minutes previous to these utterances, Elijah had broken the organ by pulling off its back, and his friend's mother had fixed it for him. Now Elijah is reporting this to his own mother and says (38a) using the transitive causative form, followed immediately by (38b) using the intransitive noncausative form. Several minutes later he goes back to playing with the organ and says (38c), again in the intransitive noncausative form. Some 20 minutes later, still talking to his mother but now without the organ, Elijah spies a Christmas decoration on the wall that his brother put up and comments on it. In this last utterance he again uses the verb root aargik- as a lexical causative, this time in the antipassive form, as shown in (38d).

(38) (Elijah 2;9)

a. Anaanangata Jaajiup aarqirataakainnatanga anaana-ngata Jaaji-up mother-ERG.3Ssg George-ERG.SG

aarqik-rataaq-kainnaq-janga

fix-PAST-PAST-PAR.3sS.3sO

'George's mom fixed it just a little while ago.'

b. Aarqiquq.

aarqik-vuq

fix-IND.3sS

'It's fixed.' 
c. Aarqirataakainnatuq. aarqik-rataaq-kainnaq-juq fix-PAST-PAST-PAR.3sS

'It got fixed a little while ago.'

d. Putulik qitinnguutiu pingani aarqisuijuvini! Putulik- $\phi$ qitinnguuti-up pi-nganik Putulik-ABS.SG Christmas-ERG.SG thing-MOD.3Ssg aarqisuk-i-juq-viniq fix-ATP-PAR.3sS-PAST

'Putulik fixed a Christmas decoration!'

It is evident from these data that these children are able to use appropriately the intransitive and transitive variants of at least some verbs participating in the causative alternation at the ages considered.

4.3.3. Lexical-causative overgeneralization. Interestingly, several examples of lexical-causative overgeneralization also appear in the data from two children, Sarah and Louisa, some months after morphological causatives begin appearing in their speech. Each of these is a case in which the child in question has used in a lexical-causative structure a verb that does not permit this alternation in the adult language. These are examples such as those reported in Bowerman (1974) and many subsequent studies of causative acquisition (e.g. Lord 1979; Berman 1982; Figueira 1984; Morikawa 1990). For Louisa, none of these overgeneralized utterances are commands, but rather declaratives and questions. Thus, what seems to be the case is that Louisa still assumes at this age that the overt causative morpheme is only for imperatives, and that other causative structures do not need an overt morpheme. For Sarah, the overgeneralization errors are all in command utterances.

Sarah has four such utterances at age $2 ; 4$. In one situation, she is telling her father to give milk to a doll, using the utterance in (39a), without the requisite causative morpheme. Her father responds with (39b), which includes this morpheme, telling Sarah to give the doll milk herself.
(39) a. (Sarah 2;4)
*Amaamaguk. amaama-guk
suckle-IMP.2sS.3sO
'Drink milk it.'

b. (Sarah's father)

Amaamatigiartuliruk

amaama-tit-giartuq-liq-guk

suckle-CAUS-in.order.to-POL-IMP.2sS.3sO

'Make it drink milk.'

In another situation, Sarah requests assistance in going to the washroom. She says the utterance in (40a), without the causative morpheme, while her mother responds with (40b), which does contain the causative morpheme.

(40) a. (Sarah 2;4)

*Quigiartulaunnga.

qui-giartuq-lauq-nnga

urinate-in.order.to-POL-IMP.2sS.1sO

'Pee me.'

b. (Sarah's mother)

Quitilagit? ... Tilaurlagit?

qui-tit-lagit $\quad . .$. tit-lauq-lagit

urinate-CAUS-IMP.1sS.2sO ... CAUS-POL-IMP.1sS.2sO

'Shall I help you pee? ... Shall I help you?'

Two other utterances do not have immediate adult models for comparison. In (41), Sarah asks her mother to let her go outside, while in (42) she asks her mother to put her doll to bed. Neither of these utterances uses the requisite causative morpheme; utterances from older children and adults that correctly use the causative morpheme with the same verb root are given for comparison in the (b) examples. Note in (42) that sinik- is the adult-lexicon counterpart to the baby word ammu-.

(41) a. (Sarah 2;4)

*Anilaunnga.

ani-lauq-nnga

go.out-POL-IMP.2sS.1sO

'Go me out.'

b. (Elijah 2;7)

Kinamut anititaulaartunga?

kina-mut ani-tit-jau-laaq-junga

who-ALL.SG go.out.-CAUS-PASS-FUT-PAR.IsS

'Who will let me go out?' [lit. 'By whom will I be made to go out?']

(42) a. (Sarah $2 ; 4)$

*Ammuguk.

ammu-guk

sleep-IMP.2sS.3sO

'Sleep it.' 
b. (Lizzie's mother)

Atii sinitilauruk takutillunga.

atti sinik-tit-lauq-guk

okay sleep-CAUS-POL-IMP,2sS.3sO

taku-tit-lunga

see-DIFF.SUBJ-ICM.1sS

'Okay, put it to sleep while I watch.'

Louisa has some 15 examples of lexical-causative overgeneralizations in her data between 3;2 and 3;5. Most of these are with verbs that forbid the lexical-causative alternation in the adult language, as in (43) through (44), (47), and (49). In the first example, Louisa is playing in the bedroom while being taped by the researcher. She has gone inside the clothes closet and upon trying to exit it discovers that the bed has gotten in the way of her being able to fully open the door. She asks the researcher to move the bed, but the researcher does not comply as quickly as Louisa would like. Louisa then tries to tempt the researcher by offering her gum, saying (43a). However, the noun root kutsuk- 'gum' does not permit the lexical causative; Louisa should instead use the sentence in (43b) with the noun root and causative morpheme (permissible in colloquial speech), or the sentence in (43c) with a noun-incorporation structure and causative morpheme.

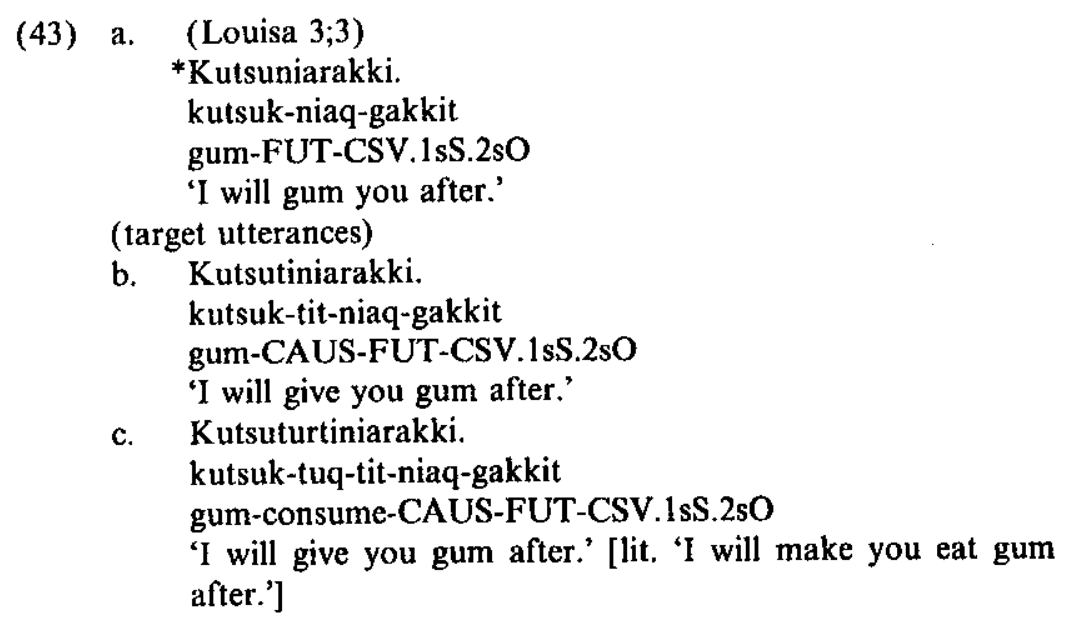

In the next utterance Louisa makes a similar error. She has set up a pretend grocery store at a night table in the bedroom that has been the focus of play for several short periods during this taping session. Just prior to the utterance in (44a) Louisa has returned to the grocery store and uses (44a) to invite the researcher to once again participate in the grocery-store interaction by offering to act as cashier to let the researcher buy something at the store. However, the verb niuviq- 'buy' does not permit the causative alternation; once again Louisa should use the causative morpheme to encode the notion of causation here, as shown in (44b).

(44) a. (Louisa 3;5)

*Niuvirialaurlagit?

niuviq-giaq-lauq-lagit

buy-begin-POL-IMP.1sS.2sO

'Want me to go buy you?'

(acting as cashier in a pretend store)

b. (target utterance)

Niuvirtilaurlagit?

niuviq-tit-lauq-lagit

buy-CAUS-POL-IMP.1sS.2sO

'Want me to let you buy something?'

A series of examples shows lexical-causative overgeneralization with the verb root itsiva- 'sit'. One of these is shown in (45). Louisa has taken a number of stuffed animals and dolls to the stairs and is carrying them up and down. She throws up one baby with moving limbs that can sit by itself, and the researcher makes it sit properly in the hall at the top of the stairs. Louisa comes up the stairs and is pleased with the seated doll. She produces the utterance in (45a) while she is looking at the doll and sitting down beside it; the adult target form is in (45b).

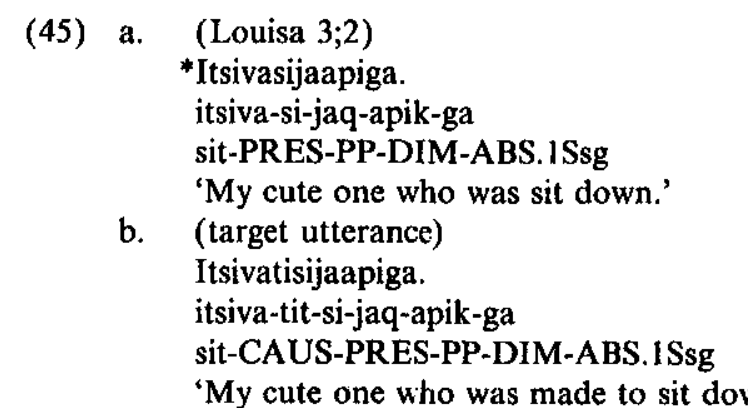

The example in (46) is one in which both lexical and morphological causatives are permitted on the relevant verb root in appropriate situational contexts. In this situation, Louisa's friend comes over to play and brings with her a small pe ppy. Louisa wants to let the puppy into the house, or at least into the porch, but her mother is against it. In (46a), 
Louisa tells her mother that she wants the dog inside. However, Louisa here uses the lexical-causative form indicating direct causation, shown in (46a), when she should instead use the morphological-causative form indicating indirect causation as in (46b).

(46) a. (Louisa 3;2)

*Itirumajarali.

itiq-guma-jara-li

enter-want-PAR.1sS.3sO-but

'But I want to make it enter [e.g. by carrying it inside].'

b. (target utterance)

Itirtigumajarali.

itiq-ti-guma-jara-li

enter-CAUS-want-PAR.1sS.3sO-but

'But I want to let it enter [e.g. by opening the door so it can come in].'

Finally, a series of utterances shows Louisa alternating between use and omission of the causative morpheme with the same verb root, ijukkaq'fall', which requires a causative morpheme in adult speech. Louisa has amassed a pile of stuffed animals at the top of the stairs and is pushing them down with some occasional help from the researcher. At the top of the stairs, she says (47a) just before pushing one stuffed animal down the stairs. The adult target is in (47b).

(47) a. (Louisa 3;2)

*Ijukkasi ... aalai ijukkasijara.

ijukkaq-si ... aalai ijukkaq-si-jara

fall-PRES ... okay fall-PRES-PAR.1sS.3sO

'Fall ... okay, I'll fall it.'

b. (target utterance)

Ijukkatitara.

ijukkaq-tit-jara

fall-CAUS-PAR.1sS.3sO

'I'll make it fall.'

Then later she says (48) when warning the researcher not to push a stuffed animal down the stairs.

(48) (Louisa 3;2)

Ijukkatinagu.

ijukkaq-tit-nagu

fall-CAUS-ICM.NEG.XxS.3sO

'Don't make it fall.'
Later she asks the researcher if she should push another stuffed animal down the stairs, using (49a). The sentence in (49b) shows the adult target.

(49)

(Louisa 3;2)

alagu?

jjukkaq-lagu

fall-IMP.1sS.3sO

'Shall I fall it?'

b. (target utterance)

Ijukkatilagu.

ijukkaq-tit-lagu

fall-CAUS-IMP.1sS.3sO

'Shall I make it fall?'

Finally, she says (50) asking the researcher to push the stuffed animal down the stairs.

(50) (Louisa 3;2)

Ijukkatilauruk.

ijukkaq-tit-lauq-guk

fall-CAUS-POL-IMP.2sS.3sO

'Make it fall.'

Louisa only uses the causative morpheme with the verb ijukkaq-at this age, but it appears here that she is trying to work out, at least with this verb, whether or not an overt causative is required. Note again here that the causative morpheme is used in exactly those cases in which commands are given, while the lexical causative is used in exactly those utterances that are not commands.

It does not seem to be the case that all the verbs involved in lexicalcausative overgeneralizations fall into one syntactic or semantic class: they include both unergative and unaccusative type verbs, as well as verbs of motion, bodily function, position, and obtaining. In addition, verbs of these syntactic and semantic classes are used correctly, even by the same children during the same period. Thus, the impression given is one of verb-by-verb learning rather than learning of verb categories all at once, or by semantic or syntactic classes.

4.3.4. Discussion. Data from children in stage three of causative acquisition in Inuktitut indicates the beginning of adultlike use of causative structures. Both morphological and lexical causatives are used with a variety of different verb roots and inflection types, and alternations between both types of causative forms and noncausatives with the same verb roots indicate that the children are learning to manipulate the 
linguistic resources of causation, Additionally, lexical-causative overgeneralizations in data from two children suggest that at least these children are beginning to clearly understand the causative component in lexical causatives.

Although the number of verb roots used in these constructions is not high enough to make any concrete conclusions about children's verbcategory formation with respect to the two types of causatives, data nonetheless suggest verb-by-verb rather than class-based learning. No clear developmental progression occurs regarding which verbs or classes of verbs appear first in each of these structures. Lexical-causative overgeneralization is also not restricted to one syntactic or semantic category. What does seem clear is that children use either a morphological or a lexical causative with a given verb root and virtually never use a morphological causative with verb roots that take both lexical and morphological causatives. Thus they seem to at least initially define two distinct classes of verbs without any overlap, though overlap does exist in the adult language

In terms of the phasal approach to development set out in the introduction, the children at this stage seem to be in the range of the third interim schemata and the fourth rule knowledge phases. The morphological causative is used with a variety of different verbs, and the lexical-causative overgeneralization errors reveal strict rule application typical of the fourth phase. Finally, the verb classes being more strictly defined than those in the adult language also seems consistent with phase-four development.

\section{Conclusions}

This study has found that the acquisition of causative structures in Inuktitut between $1 ; 0$ and 3;6 can be divided into three stages. In the first stage, no morphological causatives and only rudimentary lexical causatives are used, though presumably without understanding of the causative component of the latter. During the early one-morpheme period, both these causative types are represented by only one morpheme, usually a verb root but also occasionally a subject or object nominal. During the two-morpheme period some lexical causatives appear, while morphological causatives tend to be represented by alternative formulations of utterances. It is highly unlikely that children have categorized their verbs in any way with respect to causatives during this stage.

In the second stage of causative acquisition, morphological causatives are used in three nontypical forms: with no inflection, with no verb root, and in fixed forms. Each of these three types of structures shows little regard for the verb root in question in the utterance and rather seems to constitute a strategy to avoid the verb root or its associated argument structure. In addition, all of these utterances are either imperatives or first person suggestions, indicating that commands may serve as a trigger for the appearance of morphological causatives, and that children are thinking much more about the command component of these utterances than about the categories of verbs involved. Lexical-causative utterances appear at this stage with a wider range of fairly frequent verbs than in stage one. Although some of the data indicate the beginning of productivity of lexical causatives, such as alternations between causative and noncausative utterances with the same verb root, other data including the appearance of many verbless forms indicate confusion over which verbs go with which types of causatives.

Stage three reveals more adultlike use of both types of causatives. Both lexical and morphological causatives appear with a number of different verb roots and inflection types though no developmental pattern of syntactic or semantic verb classes used in these constructions is evident. Alternations between causative and noncausative uses with the same verb root of both the causative types suggest developing productivity in these structures. Finally, lexical-causative overgeneralizations in two of the children indicate that these children are beginning to understand the causative component of the lexical causatives, and that the development of two verb categories with respect to causative constructions takes place on a verb-by-verb basis.

The data from Inuktitut are quite consistent with findings from English and Hebrew outlined in the introduction and thus support an empirical approach to language acquisition, at least in this domain. Evidence in all three languages indicates that children begin their production of verbs in causative situations by using unanalyzed forms. There is no indication in the Inuktitut data that the children have any idea at the beginning of producing these structures of which verbs go with which causative type. Rather, they seem to be mostly avoiding verb roots and instead concentrating on the command component of causatives. Later data indicate a verb-by-verb learning procedure, since no classes of verbs are evident either in the causatives correctly produced or in the lexical-causative overgeneralizations. Once a substantial-enough verb category has been established, children begin to productively apply rules of causative formation to verbs in this category; occasionally overgeneralizing to verbs they have not yet categorized. Finally, a set of adultlike categories is established.

The overall developmental pattern seen in these data is also consistent with the general phasal vitw of cognitive and linguistic development 
outlined in the introduction. In their categorization of verbs with respect to causative structures, Inuit children clearly pass through the first four phases of development. They begin with rote knowledge: a few individual lexical and later morphological causatives as unanalyzed amalgams. Then they move into a phase of early modifications in which a few frequent items are contrasted, as in the lexical-causative alternations produced in stage two. Finally, they move into the phases of interim schemata and rule knowledge, in which lexical-causative overgeneralization errors occur, and in which categories of verbs taking morphological and lexical causatives do not overlap at all although they do overlap in adult language. Children presumably move into the fifth endstate usage stage sometime around or after $3 ; 6$.

Received 28 July, 1997

Revised version received

20 May 1998

Max Planck Institute for Psycholinguistics, Nijmegen

\section{Notes}

- I wish to thank Martha Crago for kindly allowing me to use her data, as well as all the Inuit children and families involved in both studies, and Kativik School Board for providing such generous research support. Jeannie May and Lizzie Ningiuruvik provided invaluable help as Inuktitut language consultants in analyzing and interpreting the data. Thanks also to James Anglin, Melissa Bowerman, Stephen Levinson, and two anonymous reviewers for helpful comments on previous versions of this manuscript, and to Kenneth Drozd for first pointing out to me the link between causatives and imperetives in the data. Financial support for this work was gratefully received from the Social Sciences and Humanities Research Council of Canada and the Kativik Schoo Board Research Committee. Correspondence address: Max Planck Institute for Psycholinguistics, P.O. Box 310, 6500 AH Nijmegen, The Netherlands. B-mail: allen@mpi.nl.

1. Karmiloff-Smith uses the term phases, while Berman uses the term steps. I will use the term phases here to avoid terminological confusion, given that the overall approach to development is most commonly known as a phasal approach. My use of the term stage to indicate different periods of development with relation to the causative in Inuktitut is meant to differentiate these periods from the general development phases. The term stage is not used in a technical sense (e.g. Karmiloff-Smith 1986).

2. The following grammatical abbreviations are used in English glosses:

Nominal case: $\mathrm{ABS}=$ absolutive; $\mathrm{ALL}=$ allative; $\mathrm{CND}=$ conditional; $\mathrm{ERG}=$ erga tive; $I C M=$ incontemporative; $L O C=$ locative; $M O D=$ modalis

Verbal modality: $\mathrm{CSV}=$ causative; IMP = imperative; $\mathrm{IND}=$ indicative; $I N T=$ interrogative; PAR = participial (functionally equivalent to indicative in the dialect of Inuktitut discussed here).

Word-internal morphology: AGENT $=$ agent; ANA $=$ anaphoric (out of field); ATP = antipassive; CAUS = causative; DIFF.SUBJ = different subject from main clause; $\quad$ DIM $=$ diminutive; $\quad$ EMPH $=$ emphatic; $\quad$ FUT = future; $\quad$ NEG = negative; NOM $=$ nominalizer; $P A S S=$ passive; $P A S T=$ past; $P O L=$ politeness (preceding imperative inflection); $P P=$ passive participle; $P R E S=$ present; $R E P=$ repetitive; RSP $=$ reported speech

Verbal inflection (c.g. PAR.3sS): $1=$ first person; $2=$ second person; $3=$ third person (disjoint); $4=$ fourth person (third person coreferent); $X=$ any person; $B=$ singular; $d=$ dual; $p=$ plural; $x=$ any number: $S=$ subject; $O=$ object.

Nominal inflection (e.g. ABS.SG): $\mathrm{SG}=$ singular; $\mathrm{PL}=$ plural.

Possessed nominal inflection (e.g. ERG.3Ssg): $l=$ first person possessor; $2=$ second person possessor; $3=$ third person possessor; $S=$ singular possessor; $s \mathrm{~g}=$ singular possessum; $d u=$ dual possessum.

3. In this utterance Elijah uses an incorrect verbal inflection, possibly reflecting only a pronunciation error. The inflection on the final word in the utterance should be -gavinga (CSV.2sS.1sO). However, this error does nol affect the use of the causative.

4. Louisa should use a vialis case marker -ngagut here since the car rolls underneath the extension cord to the other side, instead of stopping under the cord as the allative case implies. However, this error does not affect the use of the causative in this utterance.

\section{References}

Allen, Shanley E. M. (1996). Aspects of Argument Structure Acquisition in Inuktitut. Amsterdam: Benjamins.

-; and Schröder, Heike (i.p.). Preferred argument structure in early Inuktitut spontaneous . In Preferred Argument Structure: Grammar as Architecture for Function, John W. Du Bois, Lorraine E. Kumpf, and William J. Ashby (eds.). Amsterdam: Benjamins.

Berman, Ruth (1982). Verb-pattern alternation: the interface of morphology, syntax, and semantics in Hebrew child language. Journal of Child Language 9, 169-191.

(1986). A step-by-step model of language acquisition. In Stage and Structure: Reopening the Debate, Iris Levin (ed.). Norwood, NJ: Ablex.

-(1988). Word class distinctions in developing grammars. In Categories and Processes in Language Acquisition, Yonata Levy, Izchak M. Schlesinger, and Martin D. S. Braine (eds.). Hillsdale, NJ: Erlbaum.

-(1993a). Developmental perspectives on transitivity: a confluence of cues. In Other Children. Other Languages: Issues in the Theory of Language Acquisition, Yonata Levy (ed.). Hillsdale, NJ: Erlbaum.

-(1993b). Marking of verb transitivity by Hebrew-speaking children. Journal of Child Language 20, 641-669.

Bloom, Lois (1970). Language Development: Form and Function in Emerging Grammars. Cambridge, MA: MIT Press.

Bowerman, Melissa (1973). Early Syntactic Development: A Cross-Linguistic Study with - (1974) Rearning the stnish. Cambridge: Cambridge University Press.

-(1974). Learning the structure of causative verbs: a study in the relationship of cognitive, semantic and syntactic development. Papers and Reports on Child Language Developmen 8, 142-178.

-(1982). Starting to talk worse: clues to language acquisition from children's late speech errors. In U-Shaped Behavioral Growth, S. Strauss (ed.). New York: Academic Press.

-(1990). Mapping thematic roles onto syntactic functions: are children helped by innate linking rules? Linguistics $28,1253-1289$. 


\section{S. E. M. Allen}

What is learned in acquiring word classes: a step toward an . Acguisition, Brian MacWhinney (ed). Hillsdale, NJ: Erlbaum.

; Brody, Ruth E.; Fisch, Shalom, M.; Weisberger, Mara J.; and Blum, Monica (1990). Can children use a verb without exposure to its argument struct Language 17, 313-342.

First Language: The Early Stages. Cambridge, MA: Harvard University Press.

Causative verb formation and other verb-deriving morphology. In Languge Typology and Syntactic Description, vol. 3, Timothy Shopen (ed.). Cambridge: Cambridge University Press.

Cambridge University Press. -(1989). Languto

(1988). Culurat context in communicative interaction of young Inui Crago, Martha B. (1988). Cultural context in comilion, McGill University.

children. Unpublished doctoral dissertation, McGill University. Figueira, Rosie Attic (1984). On the development of the

hypothesis. Journal of Child Language 11, Gitan (1990). The structural sources of verb meaning Languge Acquista 3-55.

3-55.

Language 13, 317-334. Karmiloff-Smith, Annette (1986). Stage/structure versus phase/process in mebate, Iris Levin tic and cognitive development.

(ed.). Norwood, NJ: Ablex. -(1992). Beyond Modularity:

Cambridge, MA: MIT Press.

Lieven, Elena V. M. (1996). How general is early syntactic learning. Paper presented at the Seventh International Congress for the Study of Child Languge, Istanbul, Turkey.

fil me down": children's generalizations rega Lord, Carol (1979). "Don't you fall me down". childen's gelopment 17, 81-89.

and transitivity. Papers and Reports on Child Language Delop of Maratsos, Michael (1983). Some current issues in the study of child lang.

Handbook of Child Psychology, Paul H. Mussen (cd.). New York. Whacesses in Language

- (1988). The acquisition of formal word classes. In Categories andin D. S. Braine (eds.) Acquisition, Yonata Levy,

Hillsdale, NJ: Erlbaum.

-; Gudeman, Roxanne; Gerard-Ngo, Poldi; and DeHart, Ganie (1987). A study in novis word learning: the productivity of the causative. In

Brian MacWhinney (ed.). Hillsdale, NJ: Erlbaum. Marcus, Gary M.; Pinker, Steven; Ullman, Michael; Hollander, Michelle, Rosographs of the and $\mathrm{Xu}$, Fei (1992). Overregularization in

Society for Research in Child Development 57. Morikawa, Hiroko (1990). Acquisition of transitivity in Japanese: early use of

intransitive verb pairs. Working Paper in Language Development language. In Categories Ninio, Anat (1988). On formal grammatical categories in earchak M. Schlesinger, and Martin and Processes in Language Acquisition, Yon

D. S. Braine (eds.). Hillsdale, NJ: Erlbaum. Pederson, Eric (1991). Subtle semantics: universals in the polysemy of Rornia, Berkeley.
Pinker, Steven (1984). Language Learnability and Language Development. Cambridge, MA: Harvard University Press.

Pye causative alternation. In Other Children Other Languages: Issues in the Theory of Language Acquisition, Yonata Levy (ed.). Hillsdale, NJ: Eribaum.

(ed.). Hillow Acquisition of English Syntax. Radford, Andrew (1990).

Cambridge, MA: Blackwell. Shibatani, Masayoshi (1976). The grammar of causative constructions. a con York: Academic Grammar of Causative Constructions, Masayoshi Shibatani (ed.). New York: Academic

Press.
Talmy, Leonard (1976). Semantic causative types. In The Grammar of Causative Talmy, Leonard (1976). Semi Shatani (ed.). New York: Academic Press.

Constructions, Masayoshi

Tomasello, Michael (1992). First Verbs: $A$ Cas

Cambridge: Cambridge University Press. Valian, Virginia (1991). Syntacic

children. Cognition 40, 21-81. 